\title{
Intestinal permeability in Crohn's disease
}

\author{
M S MURPHY, ${ }^{*}$ E J EASTHAM,${ }^{*}$ R NELSON,${ }^{*}$ A D J PEARSON,${ }^{*}$ AND M F LAKER $\dagger$ \\ Departments of ${ }^{*}$ Child Health and +Clinical Biochemistry, University of Newcastle upon Tyne
}

SUMmARY Crohn's disease may present insidiously, especially in childhood, and diagnosis may be delayed. In addition, the clinical assessment of the extent of disease activity may be inaccurate. Using mannitol and lactulose as probe molecules we have carried out a cross sectional study of intestinal permeability in patients with active Crohn's disease $(n=17)$ and control subjects $(n=31)$. Activity was assessed by an activity index score. The lactulose:mannitol urinary excretion ratio was significantly increased in Crohn's disease. Overall sensitivity was $82 \%$, and $92 \%$ when activity was moderate or severe. When permeability was compared with the activity index there was a significant correlation among patients. In five patients studied longitudinally a significant correlation was also present. Measurement of intestinal permeability is non-invasive, and may be useful both as a screening test in patients with non-specific symptoms, and for the assessment of the extent of disease activity in patients with Crohn's disease.

The clinical onset of Crohn's disease is often insidious, with vague symptoms, and there may be a delay of several years before the definitive diagnosis is made. ${ }^{1}$ A simple, non-invasive technique for use as a first line of investigation in children would be of considerable value in cases where suspicion is aroused. The clinical assessment of the extent of disease activity in Crohn's disease may be inaccurate,$^{2}$ and an objective measure of intestinal inflammation would be useful in management.

Abnormalities of intestinal permeability have been shown in children with various gastrointestinal diseases, including coeliac disease, ${ }^{3}$ infective gastroenteritis, ${ }^{4}$ and cystic fibrosis. ${ }^{5}$ In a previous study, using mannitol and lactulose as probe molecules, we found abnormal permeability in a group of eight children with active Crohn's disease affecting the small bowel. ${ }^{3}$

In this paper we report the results of a further study of intestinal permeability in Crohn's disease in childhood. This was carried out to evaluate this technique further as a screening test for Crohn's disease. In addition we have compared the intestinal permeability in these children with an activity index score $^{2}$ to evaluate its potential for the assessment of the extent of disease activity.

\section{Subjects and methods}

Sugar permeability studies were performed in 17 patients (age range 6-16 years; 10 boys) in whom
Crohn's disease had been diagnosed by conventional clinical, radiological, endoscopic, or histological criteria. In all cases the small bowel was affected. The results of the studies were compared with those obtained from 31 healthy children (age range 2-13 years; 18 boys).

The subjects were assessed by one of two paediatric gastroenterologists (EJE and $\mathrm{RN}$ ) before the permeability studies were carried out, and a clinical judgment of the extent of disease activity was made; disease activity was graded subjectively as 'inactive', 'mild', 'moderate', or 'severe'. Simultaneously, using the criteria proposed by van Hees $e t l^{2}$ the activity index score was calculated for each patient. The activity index is based on nine variables that include specific clinical observations, and also serum albumin concentration and erythrocyte sedimentation rate ( $\mathrm{mm}$ in the first hour). This scoring system was designed to provide an objective and quantitative assessment of inflammatory activity in patients with Crohn's disease.

In addition to studying the group cross sectionally, four of the subjects were studied on two, and one on three, separate occasions to examine longitudinally the association between changes in inflammatory activity and intestinal permeability within individual patients.

After fasting overnight the subjects drank a test sugar solution containing $5 \mathrm{~g}$ mannitol and $5 \mathrm{~g}$ lactulose in $65 \mathrm{ml}$ water $(580 \mathrm{mmol} / \mathrm{l})$. They continued to fast for a further two hours, but 
thereafter a liberal intake of fluids was encouraged to increase urine flow. Five hour urine collections were made and stored in containers to which $0.2 \mathrm{ml}$ of sodium methiolate $(0 \cdot 1 \mathrm{~g} / \mathrm{l})$ had been added. The total volume was recorded and a $20 \mathrm{ml}$ sample was separated and stored at $-20^{\circ} \mathrm{C}$. This was subsequently analysed by gas liquid chromatography by previously described methods. ${ }^{67}$ The studies were carried out at home under parental supervision, unless the patient was in hospital.

The study was approved by the local ethics committee, and parents' informed consent was obtained. Results were analysed by the nonparametric Wilcoxon rank sum test, and Spearman's correlation coefficient.

\section{Results}

ACTIVITY OF CROHN'S DISEASE

At the time of the initial studies on the 17 patients four were judged clinically to have quiescent disease, but the activity index suggested that in three of these there was mild, and in one moderate, inflammatory activity. Of the 13 judged clinically to have active disease (one mild, six moderate, six severe), the activity index indicated that inflamma-

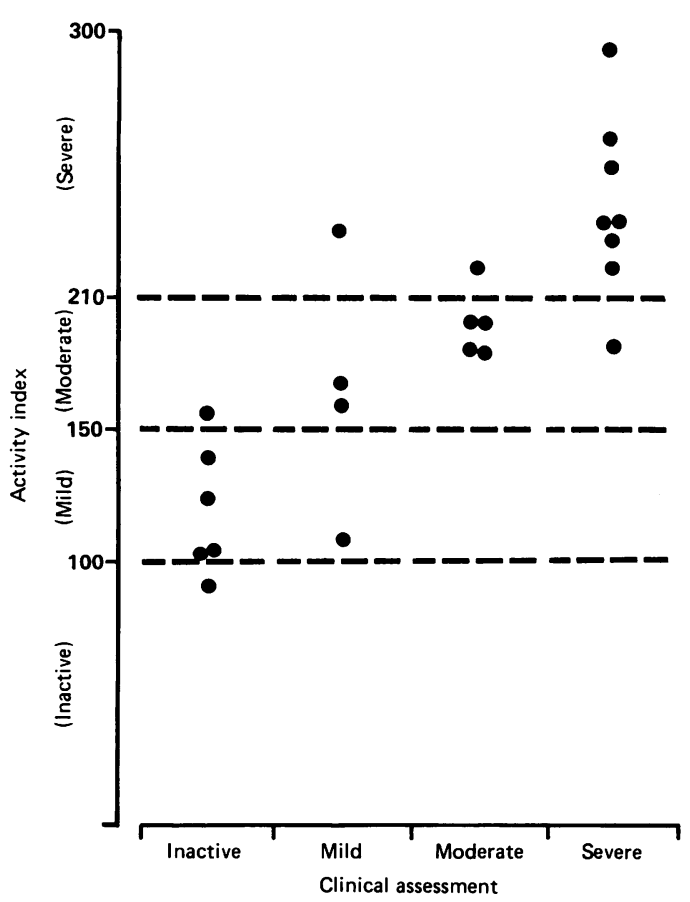

Fig 1 Comparison of disease activity judged by clinical assessment, and by an activity index score. ${ }^{2}$ tory activity was mild in one, moderate in seven, and severe in five. In fig 1 the extent of disease activity judged clinically is compared with that judged by the activity index at the time the permeability studies were carried out. This supports the view that simple clinical assessment may result in a lower estimate of the degree of inflammatory activity when compared with the more objective activity index.

\section{INTESTINAL PERMEABILITY}

The five hour urinary excretion of mannitol was not significantly different in the 17 subjects with Crohn's disease (range $5 \cdot 9-21.3 \%$ of the ingested load, median $11.1 \%$ ) compared with the control group (range $8 \cdot 5-24 \cdot 6 \%$, median $13 \cdot 2 \%$ ), and only three patients had results below the normal range. Lactulose excretion, however, was significantly greater in those with Crohn's disease (range $0 \cdot 2-2 \cdot 6 \%$ of the

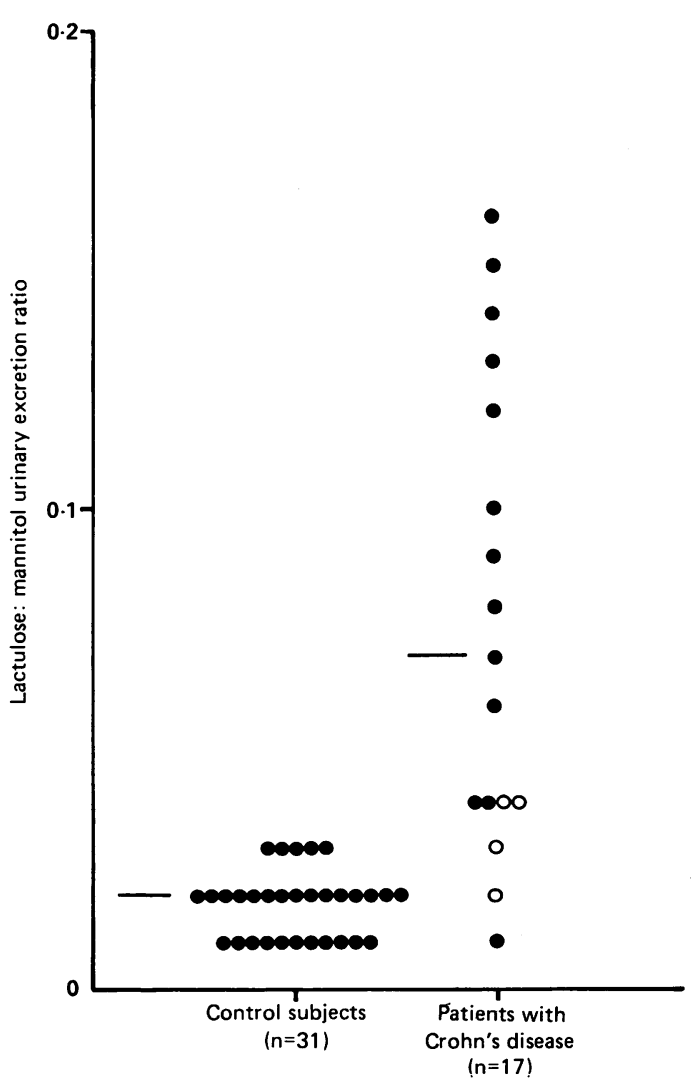

Fig 2 Lactulose:mannitol urinary excretion ratio in control subjects and patients with Crohn's disease. Bars indicate median values. Activity index showed mild activity in four patients (open circles), and moderate or severe in the remainder. 
ingested load, median $0.67 \%$ ) compared with the controls (range $0 \cdot 1-0.66 \%$, median $0.26 \%$ ) $(p<0.002)$, and 10 of the results were above the control maximum. The lactulose:mannitol excretion ratio was also significantly higher in those with Crohn's disease (range $0 \cdot 01-0 \cdot 16$, median $0 \cdot 07$ ) compared with the controls (range $0.01-0.03$, median 0.02) $(\mathrm{p}<0.0001)$, and using this index of permeability 14 were above the normal range (fig 2). The three patients whose lactulose:mannitol excretion excretion ratios were within the normal range (fig 2) were all thought clinically to have quiescent disease, although the activity index did suggest mild inflammatory activity in two and moderate activity in one.

CORRELATION BETWEEN PERMEABILITY AND DISEASE ACTIVITY

The correlation between the five hour urinary excretion of mannitol and the activity index was not significant $\left(r_{s}=0.40 ; p=0.06\right)$. There was a moderately strong correlation, however, between lactulose. excretion and the activity index $\left(r_{s}=0 \cdot 61\right.$; $\mathrm{p}<0.01$ ) (fig 3), and also between the lactulose:mannitol ratio and the activity index $\left(r_{s}=0.59 ; p<0.01\right)$ (fig 4). There was also a significant correlation between the changes in activity index and in the

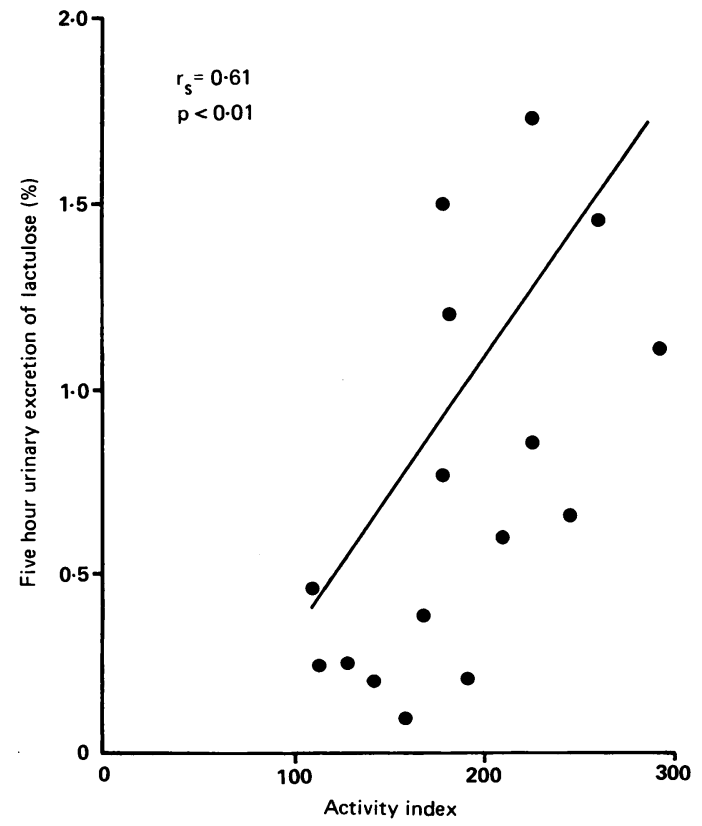

Fig 3 Five hour urinary excretion of lactulose expressed as percentage of ingested dose compared with activity index.

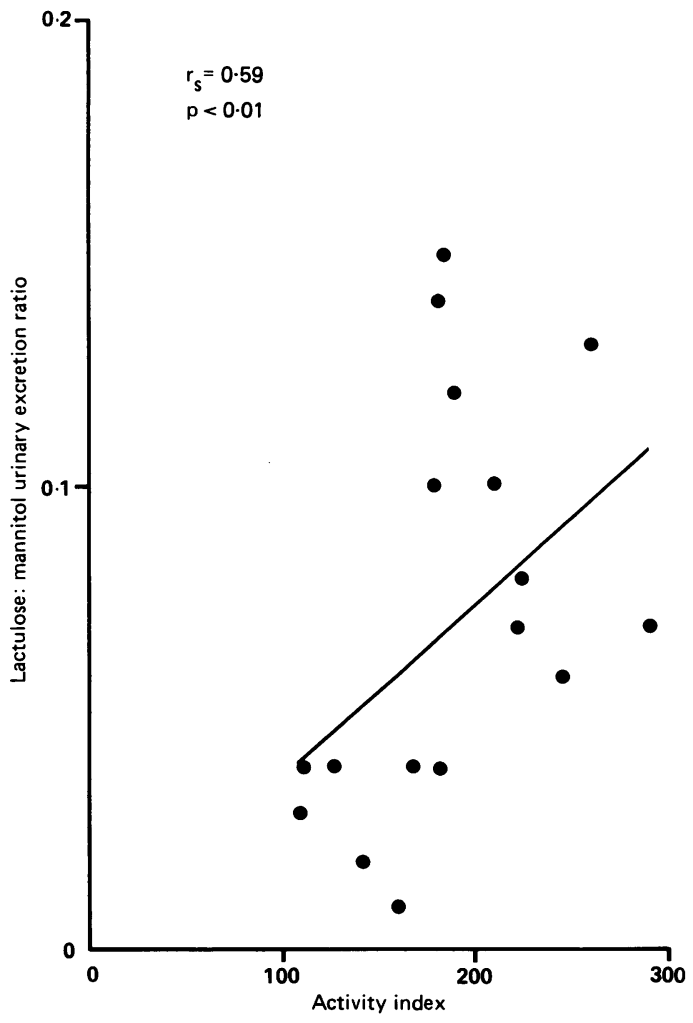

Fig 4 Lactulose:mannitol urinary excretion ratio compared with activity index.

lactulose:mannitol excretion ratio within the small group of patients studied serially $\left(r_{s}=0.83 ; p<0.05\right)$ (fig 5).

\section{Discussion}

Contrast radiology, endoscopy, and histology are usually used to establish a definitive diagnosis of Crohn's disease. There is a natural reluctance, however, to subject patients to expensive, time consuming, and unpleasant procedures in pursuit of a comparatively rare disease, especially if the presenting symptoms are vague. In addition, these techniques sometimes fail to show the disease, particularly if it is confined to the small bowel, where radiological studies may be inconclusive and biopsy difficult. A prolonged delay in diagnosis is most likely to occur in patients with disease confined to the small bowel in whom the more specific symptoms of colitis are absent. ${ }^{1}$

Intestinal permeability indicates the capacity of the intestinal absorptive surface to permit passive 


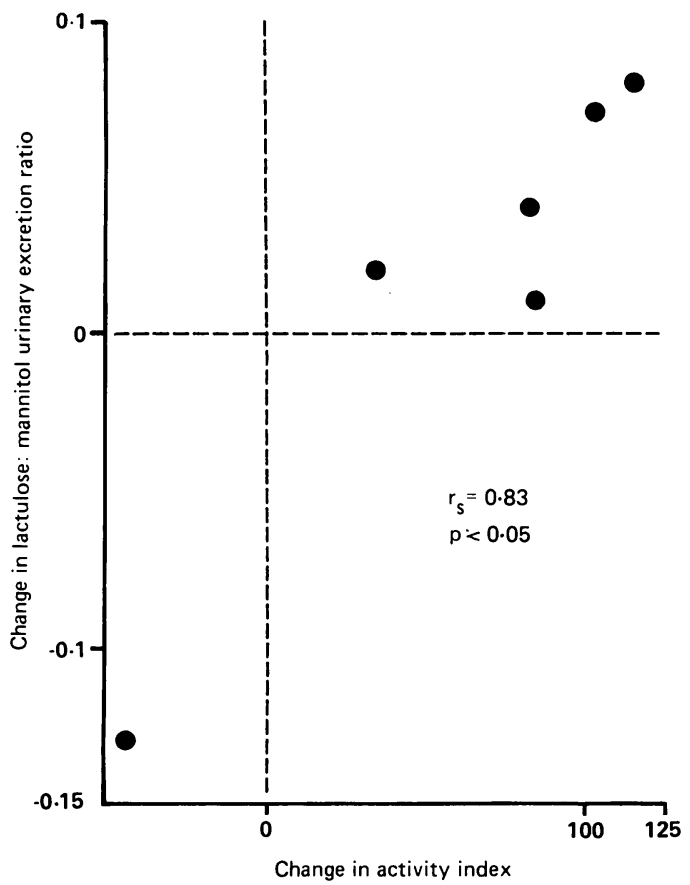

Fig 5 Change in lactulose:mannitol urinary excretion ratio compared with the change in activity index score in patients studied longitudinally.

penetration by water soluble molecules. It may be studied using orally administered probe molecules which are passively absorbed, are resistant to enzymatic digestion, are not metabolised, and are subject to quantitative renal excretion. ${ }^{8}$ Measurement of the urinary excretion of such probes then provides a measure of intestinal absorption. In previous studies of intestinal permeability in Crohn's disease the following have been used: ${ }^{51} \mathrm{Cr}$ edetic acid, ${ }^{9-11}$ polyethylene glycol (PEG 400), ${ }^{12}$ and combinations of cellobiose and mannitol, ${ }^{13}$ lactulose and mannitol, ${ }^{314}$ or lactulose and 1rhamnose. ${ }^{15}$ Together these studies have provided considerable evidence that the measurement of permeability may be a useful screening test for Crohn's disease if the small bowel is affected.

The use of a single probe molecule to assess intestinal permeability is complicated by the influence of factors other than the properties of the intestinal mucosa; gastrointestinal motility and renal function, for example, may affect absorption or excretion of the marker. By combining two probe molecules that are equally affected by such factors, the effects of these extraneous variables may be negated. ${ }^{16}$ Mannitol, a polyhydric alcohol (molecu- lar weight 182 , radius $0.4 \mathrm{~nm}$ ), is passively absorbed across the cell wall; lactulose, a synthetic disaccharide (molecular weight 342 , radius $0.54 \mathrm{~nm}$ ), seems to diffuse across the absorptive surface through intercellular pathways. ${ }^{8}$ In diseases associated with mucosal damage and loss of enterocyte surface area, absorption of small probe molecules, such as mannitol, may be reduced, and absorption of disaccharides, such as lactulose, may be paradoxically enhanced as a consequence of increased 'leakiness' of the mucosal barrier. The expression of results as the lactulose:mannitol excretion ratio has proved a useful index of intestinal permeability that is sensitive to mucosal injury in patients with coeliac disease. ${ }^{15}$ We have therefore preferred to use this technique in the study of Crohn's disease.

Although this study was carried out on subjects already known to have Crohn's disease, the results do provide further evidence that the measurement of intestinal permeability may be useful in the initial investigation of children in whom there is some suspicion of the disease. Only three of 17 children with Crohn's disease had lactulose:mannitol ratios within the normal range; these were all judged clinically to have inactive disease at the time of the study although the activity index did suggest mild activity in two and moderate activity in one. Interestingly, mannitol excretion was below the normal range in only three of the children, and lactulose excretion was above the normal range in only 10 . These results support the use of a differential sugar absorption test, rather than a test based on the use of a single probe molecule in the study of patients with Crohn's disease. Using the lactulose: mannitol urinary excretion ratio as an index of permeability, the sensitivity of the test in detecting Crohn's disease associated with at least mild inflammatory activity as judged by the activity index was $82 \%$, and in the presence of moderate to severe inflammatory activity this increased to $92 \%$.

The increased intestinal uptake of lactulose in patients with coeliac disease compared with normal subjects is greatly enhanced when the test solution is extremely hypertonic $(1500 \mathrm{mmol} / \mathrm{l}){ }^{8}$ The test solution used in our studies was moderately hypertonic $(580 \mathrm{mmol} / \mathrm{l})$, and this was used as it was considered to be a palatable drink that was likely to be acceptable to young subjects. It is possible, however, that a more concentrated solution might (as in coeliac disease) further enhance the sensitivity of the test.

Crohn's disease has a variable course, and there is considerable difficulty in the clinical assessment of the extent of disease activity. For this reason several numerical indices of activity have been developed. $^{2} 1617$ These have, however, not been 
completely satisfactory as they each have a subjective component and pronounced interobserver variation may occur. ${ }^{18} \mathrm{~A}$ number of techniques have been introduced in recent years in an affort to develop a means of objective and non-invasive assessment of intestinal inflammation. Abdominal radioisotope scanning after the intravenous administration of ${ }^{111} \mathrm{In}$ or ${ }^{99 \mathrm{~m}} \mathrm{Tc}$ labelled autologous phagocytes, ${ }^{19-21}$ or the oral administration of ${ }^{99 \mathrm{~m}} \mathrm{Tc}$ labelled sucralfate, ${ }^{22}$ may show active Crohn's disease. Alternatively, faecal excretion of the isotope may be measured after intravenous administration of ${ }^{111}$ In labelled phagocytes. ${ }^{23}$ While these techniques may be of value in detecting active disease, their role in the evaluation of the extent of disease is less clear.

Gomes et al ${ }^{15}$ using the lactulose:rhamnose excretion ratio, reported that intestinal permeability is abnormal in patients with active Crohn's disease but returns to normal when they enter remission. Our cross sectional study showed a correlation with intestinal inflammatory activity between individual patients; in addition in five patients studied longitudinally there was also a correlation with inflammatory activity within individuals. This technique may therefore have a useful role in the assessment of the extent of disease activity. To evaluate this further, studies to examine the association between intestinal permeability and the findings on endoscopic and radiological investigation are needed.

\section{References}

${ }^{1}$ Gryboski JD, Spiro HM. Prognosis in children with Crohn's disease. Gastroenterology 1978;74:807-17.

2 van Hees PAM, van Elteren, van Lier HJJ, van Tongeren JHM. An index of inflammatory activity in patients with Crohn's disease. Gut 1980;21:279-86.

${ }^{3}$ Pearson ADJ, Eastham EJ, Laker MF, Craft AW, Nelson R. Intestinal permeability in children with Crohn's disease and coeliac disease. $\mathrm{Br}$ Med $J$ 1982;285:20-1.

${ }^{4}$ Ford RPK, Menzies IS, Phillips AD, Walker-Smith JA, Turner MW. Intestinal sugar permeability: relationship to diarrhoeal disease and small bowel morphology. J Pediatr Gastroenterol Nutr 1985;4:568-74.

5 Leclercq-Foucart J, Forget PP, Van Cutsem JL. Lactuloserhamnose intestinal permeability in children with cystic fibrosis. J Pediatr Gastroenterol Nutr 1987;6:66-70.

6 Laker MF. Estimation of disaccharides in plasma and urine by gas-liquid chromatography. J Chromatogr 1979;163:9-18.
${ }^{7}$ Laker MF, Mount JN. Mannitol estimation in biological fluids by gas-liquid chromatography. Clin Chem 1980;26:441-3.

${ }^{8}$ Menzies IS. Transmucosal passage of inert molecules in health and disease. In: Skadhauge E, Heintze K, eds. Falk symposium 36. Intestinal absorption and secretion. Lancaster: MTP Press, 1984:527-43.

9 Bjarnason I, O'Morain C, Levi AJ, Peters TJ. Absorption of ${ }^{51}$ chromium labelled ethylene diamine tetraacetate in inflammatory bowel disease. Gastroenterology 1983;85:318-22.

10 Peled Y, Watz C, Gilat T. Measurement of intestinal permeability using ${ }^{51} \mathrm{Cr}$-EDTA. Am J Gastroenterol 1985;80:770-3.

11 O'Morain CA, Abelow AC, Chervu LR, Fleischner GM, Das KM. Chromium 51-ethylenediaminetetraacetate test: a useful test in the assessment of inflammatory bowel disease. $J$ Lab Clin Med 1986;108:430-5.

12 Hollander D, Vadheim CM, Brettholz E, Petersem GM, Delahunty T, Rotter JI. Increased intestinal permeability in patients with Crohn's disease and their relatives. A possible etiologic factor. Ann Intern Med 1986;105:883-5.

${ }^{13}$ Cobden I, Rothwell J, Axon ATR. Intestinal permeability and screening tests for coeliac disease. Gut 1980;21:512-8.

14 Ukabam SO, Clamp JR, Cooper BT. Abnormal small intestinal permeability to sugars in patients with Crohn's disease of the terminal ileum and colon. Digestion 1982;27:70-4.

${ }^{15}$ Gomes M De Fa, Dunne J, Logan LH, Pounder RE. Noninvasive assessment of small intestinal damage in Crohn's disease and ulcerative colitis. Gut 1983;24:A486.

16 Cobden I, Dickenson RJ, Axon ATR. Intestinal permeability assessed by excretion ratios of two molecules: results in coeliac disease. Br Med J 1978;i:1060.

${ }^{17}$ Best WR, Becktel JM, Singleton JW, Kern F Jr. Development of a Crohn's disease activity index. National Cooperative Crohn's Disease Study. Gastroenterology 1976;70:439-44.

18 Harvey RF, Bradshaw JM. A simple index of Crohn's disease activity. Lancet 1980;i:514.

19 De Dombal FT, Softley A. IOIBD report no 1: observer variation in calculating indices of severity and activity in Crohn's disease. Gut 1987;28:474-81.

${ }^{20}$ Saverymuttu SH, Lavender JP, Hodgson HJF, Chadwick VS. Assessment of disease activity in inflammatory bowel disease: a new approach using ${ }^{111}$ In granulocyte scanning. $\mathrm{Br} \mathrm{Med} J$ 1983;287:1751-3.

${ }^{21}$ Leddin DJ, Paterson WG, DaCosta LR, et al. Indium-111labelled autologous leukocyte imaging and fecal excretion. Comparison with conventional methods of assessment of inflammatory bowel disease. Dig Dis Sci 1987;32:377-87.

22 Pullman W, Hanna R, Sullivan P, Booth JA, Lomas F, Doe WF. Technetium-99m autologous phagocyte scanning: a new imaging technique for inflammatory bowel disease. $\mathrm{Br} \mathrm{Med} \mathrm{J}$ 1986;293:171-4.

${ }^{23}$ Dawson DJ, Khan AN, Miller V, Ratcliffe JF, Shreeve DR. Detection of inflammatory bowel disease in adults and children: evaluation of a new isotopic technique. $\mathrm{Br}$ Med $J$ 1985;291:1227-30.

Correspondence to Dr M S Murphy, Division of Pediatric Gastroenterology and Nutrition, The Children's Hospital, 300 Longwood Avenue, Boston, Massachusetts 02115, USA.

Accepted 10 August 1988 